\title{
PERBANDINGAN INSIDEN MUAL-MUNTAH PASCA PEMBERIAN ISOFLURAN DAN SEVOFLURAN PADA PASIEN BEDAH ORTOPEDI
}

\author{
${ }^{1}$ Erick Novrianto \\ ${ }^{2}$ Mordekai L. Laihad \\ ${ }^{2}$ Lucky T. Kumaat
}

\author{
${ }^{1}$ Kandidat Skripsi Fakultas Kedokteran Universitas Sam Ratulangi Manado \\ ${ }^{2}$ Bagian Anestesiologi dan Terapi Intensif RSUP Prof. Dr. R. D. Kandou Manado \\ Email: ericknovrianto09241@gmail.com
}

\begin{abstract}
Nausea and vomiting are common side effects after surgery and anesthesia. Nausea and vomiting can lead to dehydration, electrolyte disturbances, longer staying in the hospital, strained sutures of surgical wound, as well as the increasing of the occurence of dehiscence, hypertension, bleeding under the skin flap, risk of pulmonary aspiration due to decreased airway reflexes, and gastric mucosal ulceration. This study aimed to compare the incidence of nausea and vomiting after administration of isoflurane and sevoflurane in orthopedic surgery patients. This was an observational analytic study. Samples were all patients who underwent orthopedic surgery using inhaled isoflurane or sevoflurane form November to December 2012 conducted in Prof. Dr. R. D. Kandou Hospital Manado. Samples were obtained by using simple random sampling. The results showed that of 10 samples, there were 3 people who had nausea-vomiting (PONV); 2 people were administered inhaled isoflurane and the other one sevoflurane. The $\mathrm{P}$ values in both groups of samples $>0.05$. Conclusion: The incidence of nausea and vomiting between inhaled isoflurane and sevoflurane in orthopedic surgery were not significantly different. However, the sevoflurane group had a lower incidence than isoflurane.
\end{abstract}

Keywords: PONV, isoflurane, sevoflurane, nausea, vomiting.

\begin{abstract}
Abstrak: Mual-muntah ialah efek samping yang sering ditemukan setelah tindakan operasi dan anestesi. Mual-muntah dapat menyebabkan dehidrasi, gangguan elektrolit, waktu tinggal di rumah sakit lebih lama, jahitan luka operasi menjadi tegang, dan kemungkinan terjadi dehisensi, hipertensi, peningkatan perdarahan di bawah flap kulit, peningkatan resiko terjadinya aspirasi paru karena menurunnya refleks jalan nafas, dan ulserasi mukosa lambung. Penelitian ini bertujuan untuk membandingkan insiden mual-muntah pasca pemberian isofluran dan sevofluran pada pasien bedah ortopedi. Metode penelitian ialah observasional analitik. Sampel penelitian ialah seluruh pasien yang melakukan operasi ortopedi dengan menggunakan inhalasi isofluran dan sevofluran dalam periode November-Desember 2012 yang dilakukan di RSUP Prof. Dr. R. D. Kandou Manado. Pengambilan sampel menggunakan metode simple random sampling.Hasil penelitian memperlihatkan dari sampel sebanyak 10 orang, jumlah yang mengalami mual-muntah (PONV) sebanyak 3 orang. Jumlah sampel yang mengalami mual-muntah pada inhalasi isofluran sebanyak 2 orang dan sevofluran sebanyak 1 orang. Nilai P pada kedua kelompok sampel >0,05. Simpulan: Perbandingan insiden mualmuntah antara kelompok pengguna isofluran dan sevofluran pada bedah ortopedi tidak berbeda bermakna, namun, kelompok sevofluran memiliki insiden lebih rendah dibanding isofluran.
\end{abstract}

Kata kunci:PONV, isofluran, sevofluran, mual-muntah 
Mual-muntah merupakan efek samping yang sering ditemukan setelah tindakan operasi dan anestesi. Mual dan muntah dapat menyebabkan dehidrasi, gangguan elektrolit, waktu tinggal di rumah sakit lebih lama, jahitan luka operasi menjadi tegang, dan kemungkinan terjadinya dehisensi, hipertensi, peningkatan perdarahan di bawah flap kulit, peningkatan resiko terjadinya aspirasi paru karena menurunnya refleks jalan nafas, dan ulserasi mukosa lambung. ${ }^{1}$

Suatu penelitian melaporkan kekerapan mual-muntah (PONV) setelah pemberian anestesi dengan isofluran sebesar 34\% dan sevofluran sebesar 33\%. Analisis dari penelitian tersebut menunjukkan bahwa meningkatnya lama anestesi inhalasi berhubungan dengan meningkatnya kekerapan muntah secara signifikan. Di masa lalu mual-muntah (PONV) dianggap sebagai masalah klinis yang tidak bermasalah karena dapat sembuh sendiri, tidak pernah menjadi kronik, dan hampir tidak menyebabkan mortalitas. Kejadian mual-muntah ini lebih sering menyebabkan ketidak nyamanan dibandingkan nyeri pasca bedah. $^{2}$

Mual-muntah ini dapat terjadi pada 10$80 \%$ pasien yang menjalani pembedahan dan anestesi. Hal itu disebabkan karena besarnya faktor risiko individual dan faktor risiko anestesi. Mual dan muntah ini jarang bersifat fatal, tetapi tidak menyenangkan dan membuat pasien merasa tidak puas dengan perawatan yang dijalaninya., Insiden mual dan muntah yang terjadi dalam waktu 24 jam setelah pembedahan ialah 20-30\%. Sekitar 70-80\% kejadian terjadi pada pasien dengan risiko tinggi. Penyebab mual dan muntah diduga bersifat multifaktorial, antara lain meliputi faktor individual, anestesi, dan faktor risiko pembedahan. ${ }^{1}$

Penelitian ini bertujuan untuk mengetahui perbandingan insiden mualmuntah pasca pemberian isofluran dan sevofluran pada pasien bedah ortopedi.

\section{METODE PENELITIAN}

Penelitian ini menggunakan metode observasional analitik. Jumlah sampel ialah seluruh pasien yang melakukan operasi ortopedi dengan menggunakan inhalasi isofluran atau sevofluran dalam periode November-Desember 2012 yang dilakukan di RSUP Prof. Dr. R. D. Kandou Manado. Pengambilan sampel menggunakan metode simple random sampling.

\section{HASIL PENELITIAN}

Penelitian dilakukan dari bulan November sampai bulan Desember tahun 2012, dengan jumlah sampel 10 orang. Diantara 10 orang tersebut, yang mengalami PONV sebanyak 3 orang (30\%).

Tabel 1. Data Demografik

\begin{tabular}{cccc}
\hline Umur & $\begin{array}{c}\text { Berat } \\
\text { badan } \\
(\text { Kg) }\end{array}$ & $\begin{array}{c}\text { Inhalasi } \\
\text { yang } \\
\text { digunakan }\end{array}$ & $\begin{array}{c}\text { Lama } \\
\text { operasi } \\
\text { (menit) }\end{array}$ \\
\hline 33 & 78 & Isofluran & 20 \\
25 & 40 & Isofluran & 215 \\
19 & 65 & Isofluran & 150 \\
28 & 63 & Isofluran & 220 \\
44 & 64 & isofluran & 170 \\
17 & 68 & Sevofluran & 54 \\
50 & 70 & Sevofluran & 133 \\
46 & 60 & Sevofluran & 115 \\
28 & 61 & Sevofluran & 180 \\
34 & 63 & Sevofluran & 175 \\
\hline
\end{tabular}

Tabel 2. Perbandingan insiden mual-muntah (PONV) berdasarkan inhalasi yang digunakan

\begin{tabular}{cccc}
\hline & Isofluran & Sevofluran & Nilai P \\
\hline PONV & 20 & 10 & 1,00 \\
\hline
\end{tabular}

Tabel 3. Kejadian mual-muntah (PONV)

\begin{tabular}{ccc}
\hline Kategori & Isofluran & Sevofluran \\
\hline Tidak mual & 3 & 4 \\
Agak mual & 0 & 0 \\
Sangat mual & 2 & 1 \\
\hline Muntah & 0 & 0 \\
Retchinf & 0 & 0 \\
\hline Total & 5 & 5 \\
\hline
\end{tabular}




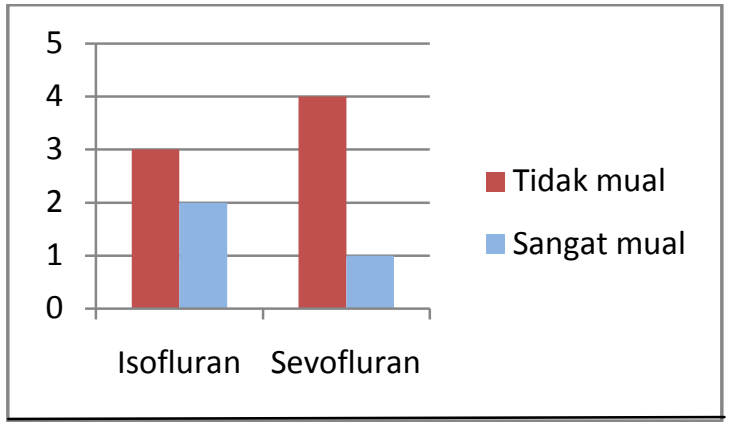

Gambar 1. Grafik insiden mual-muntah pasca operasi

Grafik dan tabel diatas menunjukkan jumlah kejadian (insiden) mual-muntah pada pasien yang menggunakan isofluran dan sevofluran. Jumlah pasien yang mengalami PONV dengan menggunakan inhalasi isofluran sebanyak 2 orang, sedangkan yang menggunakan sevofluran sebanyak 1 orang.

\section{BAHASAN}

Penelitian dilakukan di RSUP Prof. Dr. R. D. Kandou Manado dengan sampel berusia 17-50 tahun, pembedahan anestesi umum, tanpa kelainan sistemik yang berat, lama operasi tidak lebih dari 4 jam, dan tidak mengalami obesitas.

Dari hasil penelitian, nilai P pada kedua kelompok sampel >0,05. Hal ini berarti tidak ada perbedaan bermakna antara kedua kelompok sampel. Pada pengamatan saat penelitian, tidak ditemukan adanya pasien yang mengalami muntah baik pada kelompok isofluran maupun sevofluran. Kejadian mual pada kedua kelompok terdapat 3 pasien yang merasakan sangat mual; 2 pada kelompok isofluran dan 1 pada kelompok sevofluran.

Kurangnya jumlah sampel disebabkan oleh kurangnya waktu penelitian untuk mendapatkan jumlah sampel yang lebih besar sehingga perlu dilakukan penelitian lebih lanjut dengan jumlah sampel yang lebih besar agar mendapatkan perbedaan yang bermakna antara ke-2 kelompok sampel.

\section{SIMPULAN}

Dari hasil penelitian dapat disimpulkan bahwa insiden mual-muntah pasca pemberian isofluran dan sevofluran pada pasien bedah ortopedi tidak berbeda bermakna.

\section{DAFTAR PUSTAKA}

1. Nurwinarsih F. Perbandingan efektifitas premedikasi ondansetron dan deksametason dalam mencegah mual dan muntah pasca operasi [Skripsi]. Surakarta: Fakultas Kedokteran Sebelas Maret, 2009; p. 17.

2. Harijanto E. Penatalaksanaan mualmuntah pasca bedah (PONV): peran granisetron. Medicinus. 2010;23:13-4.

3. Gwinnutt CL. Catatan kuliah. Anestesi klinis (3rd ed.) Jakarta: EGC, 2011; p. 97. 